\title{
Secondary Traumatic Stress in Attorneys and Their Administrative Support Staff Working With Trauma-Exposed Clients
}

\author{
Andrew P. Levin, MD, *† Linda Albert, LCSW, $\neq$ Avi Besser, PhD, $\S$ Deborah Smith, JD,// Alex Zelenski, MBA, \\ Stacey Rosenkranz, PhD,I and Yuval Neria, PhD†\#
}

\begin{abstract}
Although secondary trauma has been assessed in various groups of mental health professionals, few studies, to date, have examined secondary trauma among attorneys exposed to clients' traumatic experiences. This study examined indicators of secondary trauma among attorneys $(N=238)$ and their administrative support staff $(N=109)$ in the Wisconsin State Public Defender Office. Attorney participants demonstrated significantly higher levels of posttraumatic stress disorder symptoms, depression, secondary traumatic stress, burnout, and functional impairment compared with the administrative support staff. This difference was mediated by attorneys' longer work hours and greater contact with clients who had experienced or had been directly involved with trauma. Sex, age, years on the job, office size, and personal history of trauma did not predict symptoms. These findings suggest a need to support attorneys experiencing these symptoms and to address high workloads as well as the intensity of contact with trauma-exposed clients.
\end{abstract}

Key Words: Attorneys, secondary traumatic stress, PTSD, depression, functional impairment, burnout.

(J Nerv Ment Dis 2011;199: 946-955)

$T^{1}$ he phenomenon of Secondary Traumatic Stress (STS; Figley, 1995) or Vicarious Traumatization (VT; McCann and Pearlman, 1990) have been described since the mid-1980s, roughly coinciding with the growth in treatments focused on clients who were victims of trauma. Originally described in therapists, secondary trauma occurs when the professional develops intrusive thoughts, avoidance and withdrawal, and symptoms of tension and disturbed sleep related to exposure to traumatic material presented by the client (Figley, 1995). In addition, the professional may develop alterations in "basic assumptions" about themselves, people, society, and safety (McCann and Pearlman, 1990). In addition to STS and VT, professionals working intensely with clients develop Burnout (BO), an accumulation of stress and the erosion of idealism characterized by fatigue, poor sleep, headaches, anxiety, irritability, depression, hopelessness, aggression, cynicism, and substance abuse (Farber and Heifetz, 1982). In this study, we examined the impact of work with clients who have experienced or have been directly involved in trauma on attorneys and their administrative support staff in the Wisconsin State Public Defender Office.

Available research among mental health and social service providers has identified several risk factors for the development of

*Westchester Jewish Community Services, Hartsdale, NY; † Department of Psychiatry, College of Physicians and Surgeons, Columbia University, New York, NY; \$Wisconsin Lawyers Assistance Program, State Bar of Wisconsin, Madison, WI; $\S$ Department of Behavioral Sciences and Center for Research in Personality, Life Transitions, and Stressful Life Events, Sapir Academic College, D. N. Hof Ashkelon, Israel; ||Assigned Counsel Division, Wisconsin State Public Defender Office, Madison, WI; \Weill Medical College, Cornell University, New York, NY; and \#New York State Psychiatric Institute, New York, NY.

Send reprint requests to Andrew P. Levin, MD, Westchester Jewish

Community Services, 141 North Central Avenue, Hartsdale, NY 10530.

E-mail: aplevin2@cs.com.

Copyright (C) 2011 by Lippincott Williams \& Wilkins

ISSN: 0022-3018/11/19912-0946

DOI: $10.1097 /$ NMD.0b013e3182392c26
STS and VT including female sex (Kassam-Adams, 1999), intensity of the exposure (Creamer and Liddle, 2005; Erikson et al., 2001; Kassam-Adams, 1999), history of previous trauma (Brady et al., 1999; Bride et al., 2007; Kassam-Adams, 1999), and less experience on the job (Pearlman and Mac Ian, 1995). Subsequent studies have suggested the primary importance of organizational and work-related factors compared with exposure (Baird and Jenkins, 2003; Devilly et al., 2009; Regehr et al., 2004) and have found no relationship with personal trauma history (Boscarino et al., 2004; Ortlepp and Friedman, 2002; Schnaube and Frazier, 1995). Risk factors for BO include female sex, overwork, the slow and erratic pace of the work, lack of success, and the tendency of the work to raise personal issues (Jenkins and Baird, 2002; Maslach et al., 2001).

Drawing on the concepts of STS and VT, the "clinical" (practice-related) law literature was the first to address the impact of lawyer-client relationship on the attorney (Meier, 1993; Silver, 1999) and the need for increased training of attorneys in managing the "face-to-face, long-term, and intensely personal relationship" that develops between client and attorney (Allegretti, 1993, p. 7). Early quantitative studies of attorneys focused on rates of depression, identifying a $20 \%$ rate of clinically significant depression in the attorneys who were surveyed (Benjamin et al., 1990; Eaton et al., 1990).

Only a handful of studies have attempted to characterize and quantify secondary trauma and BO symptoms experienced by attorneys and delineate their relationship to risk factors. Using semistructured interviews of 23 Canadian prosecutors working with "sensitive cases" involving domestic violence and incest, Gomme and Hall (1995) found symptoms of demoralization, anxiety, helplessness, exhaustion, and social withdrawal that were qualitatively linked to high caseloads and long work hours. Lynch (1997) reported that public defenders ranked work overload, the unpredictability of trials, the frequent lack of a defense, harsh sentences, arguing with prosecutors, and interactions with angry clients and families as the most frequent and intense sources of job stress but did not relate these to any symptom measures. More recently, Levin and Greisberg (2003) compared 55 attorneys working in family and criminal court with 87 mental health professionals and 25 social service workers. Their results indicated that compared with the other groups, attorneys demonstrated higher levels of secondary trauma and BO that were correlated with caseload. Comparing 50 attorneys working in criminal courts with 50 working in the civil arena, Vrlevski and Franklin (2008) found more depressive symptoms, subjective stress, and changes in sense of safety and intimacy among the criminal attorneys. A personal history of multiple traumas predicted higher scores on measures of vicarious trauma, posttraumatic stress, and depression. Piwowarcyzy et al. (2009) reported that among 57 attorneys specializing in asylum cases, the hours per week devoted to those cases correlated with trauma score. All three of these studies of distress in attorneys suggest a relationship between exposure to trauma and distress but suffer from small sample size, selection bias involving convenience samples, and relatively low percentage responses from the pool of possible subjects (Levin and Greisberg, 2003; Piwowarcyzy et al., 2009; Vrlevski and Franklin, 2008).

The current study sought to address those limitations in a relatively larger study, assessing the relationships between exposure to 
clients' traumatic experiences and a range of outcomes including posttraumatic stress disorder (PTSD) symptoms, depression, functional impairment, and STS and BO symptoms in attorneys and administrative support staff working at the Wisconsin State Public Defender Office. In light of previous studies, we hypothesized that a) the average number of hours working and the caseload of traumaexposed clients would predict higher symptom load and b) attorneys would experience greater symptoms than would administrative support staff because of their greater client involvement. Moreover, we conceptualized attorneys' work-related exposure (hours per week working and number of trauma-exposed clients) as mediating variables ${ }^{1}$ based on our interpretation of the literature on both exposure and STS. As such and consistent with the literature on exposure, our primary hypothesis was that c) work-related exposure would serve as a vehicle through which being directly versus indirectly exposed to clients who had experienced or had been directly involved in trauma is associated with psychological symptoms. Specifically, attorneys, in comparison with administrative support staff, were expected to report high levels of exposure, which, in turn, would be associated with their significantly higher levels of PTSD symptoms, depression, functional impairment, STS, and BO symptoms. Lastly, the study explores the relationship between personal characteristics such as age, sex, years on the job, office size, and personal trauma history and the outcome variables. Given that the findings have varied for these factors in previous studies, we did not predict specific effects for these independent variables.

\section{METHODS}

\section{Participants and Procedures}

We sampled participants for this study from the Wisconsin State Public Defender Office. At the time of the study (in early 2010) there were a total of 474 potential participants, including 307 attorneys and 167 administrative support staff, in the 38 offices across the state. The attorneys routinely interact closely with defendants in local jails, prisons, courthouses, and in their own offices. Cases run the gamut from mild violence or substance abuse to homicide and sexual offenses such as rape or child abuse. In addition to hearing first-hand accounts, the attorneys review reports and photographs and have contact with physical evidence such as bloody clothing. Administrative support staff typically performs brief financial eligibility evaluations in their offices and at times, at the jail. On occasion, defendants spontaneously relate details of their offense to the support staff, who also have contact with reports and photographs.

Potential participants received encouragement to participate in the study from the Wisconsin State Public Defender Office and the State Bar of Wisconsin as part of a program to raise awareness about stress. Survey materials were made available online by the survey office of the State Bar of Wisconsin. Potential participants received an email providing the necessary link to the questionnaires and were encouraged to complete the survey from personal computers on the job site. All subjects were provided with informed consent in the form of a cover letter at the start of the online survey packet. Proceeding to the questionnaire indicated consent. Participation was voluntary and anonymous. The research proposal was reviewed and approved by the Westchester Jewish Community Services Research Committee as well

${ }^{1}$ Baron and Kenny (1986) characterize mediation as a case in which a variable, such as exposure, functions as a "generative mechanism through which a focal independent variable [such as attorney vs. support staff] is able to influence the dependent variable of interest" (p. 1173; see also Frazier et al., 2004). Mediation occurs when an external variable such as exposure better explains a relationship between a predictor, such as being directly (attorneys) versus indirectly (administrative support staff) exposed to trauma-exposed clients, and an outcome, such as various symptoms (Frazier et al., 2004). as its board of directors and chief executive officers. Leadership at both the Wisconsin Public Defenders Office and the Wisconsin Bar also reviewed and approved the study. The final sample contains 347 participants (an overall response rate of $73.20 \%$ ) including 238 attorneys (response rate of $77.52 \%$ ) and 109 administrative support staff (response rate of $65.27 \%$ ).

\section{Measures}

\section{Background and Trauma Exposure Assessments}

Demographic and personal information included age, sex, job description (attorney versus administrative support staff), number of years on the job, average number of hours worked per week (for the previous 3 months), and size of local office (total staff) specified on a 1-to-4 scale: less than 10 (1), 10 to 20 (2), 21 to 40 (3), and greater than 40 (4). Because participants expressed a strong need to protect their anonymity, information regarding the specific office where the participant worked as well as ethnic origin was omitted.

Personal history of trauma was gathered by asking, "Have you been a victim of any of the following types of trauma? Please estimate numbers of incidents from childhood/adolescence (up to age 15)." Types of trauma were divided into six groups: a) physical assault or abuse, b) sexual assault or abuse, c) witness to violence, d) other crime victim, e) fire, and f) natural disaster. The question was repeated for age 16 years and older. Sum scores were generated for each of the age periods for the a) total number of physical and sexual assault or abuse incidents and b) total number of nonphysical/nonsexual trauma incidents.

Exposure to client trauma was assessed by asking, "How many clients have you worked with, within the last three months who had experienced or been directly involved with trauma such as death, physical assault or abuse, domestic violence, rape, violence or fire?" Participants were instructed to select the closest number on a 0 -to-5 scale: none (0), 1 to 20 (1), 21 to 40 (2), 41 to 60 (3), 61 to 80 (4), and 81 or more (5).

\section{Outcome Variables \\ PTSD symptoms}

The Impact of Events Scale-Revised (IES-R; Weiss and Marmar, 1997) was used to assess the symptoms of PTSD. This instrument is composed of 22 items derived from the PTSD criteria according to the DSM-IV (American Psychiatric Association, 1994). Respondents were asked to rate each item on a scale of 0 (not at all), 1 (a little bit), 2 (moderately), 3 (quite a bit), and 4 (extremely), according to how distressed they had been by symptoms of intrusion, hyperarousal, and avoidance over the past 7 days. All participants were asked to specifically link the symptoms to traumatic material related to a case or cases they had encountered as part of their work. No time frame was specified regarding when the material was encountered. The IES-R has good psychometric properties (Creamer et al., 2003) and has good convergent validity with other measures of PTSD (Ljubotina and Muslic, 2003). In the present study, we obtained internal consistency Cronbach's alpha reliability coefficients of $\alpha=0.80,0.82$, and 0.87 , for avoidance, hyperarousal, and intrusion, respectively. The maximum score for the scale is 88; a cutoff of 1.5 (equivalent to a total score of 33) was found to provide the best diagnostic accuracy (Creamer et al., 2003).

\section{Depressive symptoms}

The Center for Epidemiological Studies Depression Scale (CES-D; Radloff, 1977) is a 20-item scale designed to measure the severity of current depression in the general population. The items, each of which is assessed on a scale from 0 to 3, measure depressed mood, feelings of guilt and worthlessness, feelings of helplessness and hopelessness, psychomotor retardation, loss of appetite, and sleep 
disturbances (Radloff, 1977). All participants were asked to report symptoms they had felt in the past week. The CES-D is in wide use and has acceptable levels of internal consistency (Radloff, 1977). Extensive evidence from a variety of samples attests to the reliability and validity of the CES-D (Eaton et al., 2004). In the present sample, the estimate of internal consistency Cronbach's alpha reliability coefficient was 0.90 . A score of 16 or higher (of a possible maximum of 60) has been used as the cutoff point for high likelihood of clinically significant depression (Radloff, 1977).

\section{Functional impairment levels}

The Sheehan Disability Scale (SDS; Sheehan et al., 1996) was used to assess the extent to which exposure to clients' traumatic material interfered with functioning in three spheres. Participants rated the following question (in three forms): "My feelings about the clients and cases at work have disrupted my (work, social life/leisure, or family life/home responsibilities)" on a 0 -to-10 visual analogue scale with the following descriptions: none ( 0 ), mild (1 to 3 ), moderate (4 to 6 ), severe ( 7 to 9 ), and very severe (10). In the present sample, the estimate of internal consistency Cronbach's alpha reliability coefficient was 0.92 . According to the scale's authors, a score of 5 or higher for any of the three questions is associated with significant functional impairment (Sheehan et al., 1996).

\section{Levels of STS and $\mathrm{BO}$}

The Professional Quality Of Life Scale Version 5 (ProQOL5; Stamm, 2010) is a 30 -item questionnaire broken into three 10 -item groups measuring Compassion Satisfaction (CS), STS, and BO. The $\mathrm{CS}$ dimension (CS) "is about the pleasure you derive from being able to do your work well" (Stamm, 2010, p. 12), with higher scores indicating greater work satisfaction. STS items measure fear, sleep difficulties, intrusive images, or avoiding reminders of the person's traumatic experiences. BO items measure feelings of hopelessness and difficulties in dealing with work. Higher scores on these dimensions indicate more distress. Participants were instructed to answer questions with respect to their reactions and symptoms in the previous 30 days as related to work at the Wisconsin State Public Defender Office. Responses were scored on a 1-to-5 visual analogue scale, with never (1), rarely (2), sometimes (3), often (4), and very often (5). In the present sample, the estimates of internal consistency Cronbach's alpha reliability coefficients were $0.90,0.85$, and 0.83 for CS, STS, and BO, respectively. These are similar to alpha coefficients reported by Stamm (2010): $0.88,0.81$, and 0.75 for CS, STS, and BO, respectively. Analysis of the scale produces $Z$ scores that are then converted to T-scores, with a mean (SD) of 50 (10). A T-score greater than 57 for CS or greater than 56 for STS and BO are above the 75 th percentile in samples used in the development of the scale (Stamm, 2010).

\section{Data Analysis}

Descriptive statistics were first calculated for demographics, trauma history, and work and exposure variables and compared between groups using $t$-tests. Groups were compared regarding sex differences using chi-square analyses. Mean scores for the IES-R, CES-D, SDS, and the three subscales of the ProQOL5 were calculated and compared between groups using $t$-tests. In addition, the cutoff scores for each of the measures for the two groups were compared using chi-square analyses. We then performed a bivariate analysis correlating demographics, work variables, exposure and trauma history with the symptoms scales.

After these initial tests, we tested our hypotheses regarding the mediating role of work-related exposure for the outcome variables using multivariate analyses with an structural equation modeling (SEM; Hoyle and Smith, 1994) strategy that assessed measurement errors for the dependent and independent variables using AMOS software (Version 18.0.0; Arbuckle, 2009) and the maximum likelihood method. A nonsignificant chi-square value has traditionally been used as a criterion for not rejecting an SEM model; a nonsignificant chi-square value indicates that the discrepancy of the matrix of the parameters estimated based on the model being evaluated is not different from the one based on empirical data. Because of the restrictiveness of the chi-square approach for assessing model fit (Bentler and Bonnet, 1980; Jöreskog and Sörbom, 1993; Kenny and McCoach, 2003; Landry et al., 2000), we also used alternate criteria that reflect the real-world conditions of clinical research, in addition to the overall chisquare test of exact fit to evaluate the proposed models: a) the chisquare/ $d f$ ratio, b) the root mean square error of approximation (RMSEA), c) the comparative fit index (CFI), and d) the nonnormed fit index (NNFI). A model in which the chi-square/df was 2 or less, CFI and NNFI were greater than 0.95 , and the RMSEA index was between 0.00 and 0.06 with confidence intervals between 0.00 and 0.08 (Hu and Bentler, 1999) was deemed acceptable. These moderately stringent acceptance criteria clearly reject inadequate or poorly specified models while accepting for consideration models that meet real-world criteria for reasonable fit and representation of the data (Kelloway, 1998).

\section{RESULTS}

\section{Group Differences}

We first compared the attorneys and the administrative support staff groups on background and work characteristics (Table 1), workrelated exposure and personal history of previous trauma (Table 1), and the study outcome variables (Table 2). No significant differences were found with regard to age and size of local office. However, as shown in Table 1, the administrative support staff group has significantly fewer men than the attorneys group, and participants in the attorneys' group reported significantly more years on the job and of hours per week working compared with the administrative support staff group. No significant differences were found for childhood or adulthood-related exposure variables. However, as shown in Table 1, participants in the attorneys group reported working with significantly more clients who experienced or were directly involved in trauma compared with the administrative support staff group.

Comparing attorneys and support staff on outcome variables (Table 2), attorneys had significantly higher mean scores on all measures except CS, the latter being lower among attorneys than among administrative support staff. Furthermore, significantly more participants in the attorney group met screening criteria for PTSD (11\% vs. 1\%), depression (39.5\% vs. 19.3\%), functional impairment (74.8\% vs. $27.5 \%)$, BO (37.4\% vs. 8.3\%), and STS (34\% vs. $10.1 \%)$ compared with the administrative support group. Only a minority of attorneys (19.3\%) and administrative supports staff (25.7\%) reported $\mathrm{CS}$ above the 75th percentile level (the groups did not differ) compared with norms for the ProQOL5 CS.

\section{Bivariate Associations}

Table 3 provides a summary of the zero-order correlations for all of the study variables. Sex, age, years on the job, size of local office, and a personal history of childhood or adult trauma did not significantly correlate with any of the outcome variables. Group membership (attorneys $v s$. administrative support staff) was significantly associated with all outcomes, except with the ProQOL5 CS scale, with attorneys reporting higher scores for symptoms and impairment. In addition, work-related exposure as measured by the average number of hours working and the number of clients worked with in the last 3 months who experienced or were directly involved with trauma were both significantly and positively correlated with symptom measures, again with the exception of the ProQOL5 CS scale. For each of the three variables with significant correlations to outcome variables, the strongest correlations were consistently seen with BO and functional impairment. 
TABLE 1. Background and Trauma Exposure Variables Among Attorneys and Administrative Support Staff

\begin{tabular}{|c|c|c|c|c|c|c|}
\hline \multirow{2}{*}{$\begin{array}{l}\text { Background Variables } \\
\text { Sex }\end{array}$} & \multicolumn{2}{|c|}{ Attorney $(N=238)$} & \multicolumn{3}{|c|}{$\begin{array}{c}\text { Administrative } \\
\text { Support Staff }(N=109)\end{array}$} & \multirow[t]{2}{*}{ Statistic } \\
\hline & & & & & & \\
\hline Female & \multicolumn{2}{|c|}{132} & \multicolumn{3}{|c|}{94} & \\
\hline Male & Mean & SD & Mean & SD & $t(d f=343)$ & Effect Size $(d)$ \\
\hline Age & 45.72 & 11.00 & 45.07 & 11.32 & $0.50, \mathrm{~ns}$ & 0.06 \\
\hline Average number of hours working & 46.43 & 9.08 & 34.73 & 9.74 & $10.72 * *$ & 1.24 \\
\hline Size of local office & 2.39 & 1.02 & 2.53 & 1.00 & $-1.17, \mathrm{~ns}$ & -0.14 \\
\hline \multicolumn{7}{|l|}{ Trauma exposure variables } \\
\hline \multicolumn{7}{|l|}{ Childhood trauma } \\
\hline Physical and sexual abuse & 3.16 & 15.37 & 3.27 & 15.13 & $-0.60, \mathrm{~ns}$ & -0.07 \\
\hline Not physical and sexual abuse & 4.02 & 16.37 & 1.50 & 5.90 & $1.54, \mathrm{~ns}$ & 0.18 \\
\hline $\begin{array}{l}\text { Number of clients working with in the last } 3 \text { mos who } \\
\text { experienced or were directly involved with trauma }\end{array}$ & 3.20 & 1.299 & 1.98 & 1.455 & $7.70^{* *}$ & 0.89 \\
\hline $\begin{array}{l}* p<0.01 \text { (two-tailed) } \\
* * p<0.001 \text { (two-tailed). } \\
\text { ns indicates not significant. }\end{array}$ & & & & & & \\
\hline
\end{tabular}

\section{Multivariable Analyses}

\section{The Mediating Models}

In testing our primary hypothesis that work-related exposure variables mediate the relationships between groups and PTSD symptoms (IES-R), depressive symptoms (CES-D), functional impartment (SDS), and levels of STS and BO (ProQOL5), we followed Baron and Kenny's (1986) criteria for mediation, according to which, a) there must be a significant association between the predictor and criterion variables; b) in an equation including both the mediator and the criterion variable, there must be a significant association between the predictor and the mediator, and the mediator must be a significant predictor of the criterion variable; and c) there must be a decrease in the direct relationship between the independent and the dependent variables (Baron and Kenny, 1986; Kenny et al., 1998). If the significant direct relationship between the predictor and the criterion variables decreases when both the mediator and the predictor variable are included in the equation, then the obtained pattern is consistent with the mediation hypothesis. If the direct association approaches zero, the mediator fully (although not necessarily exclusively) accounts for the relation between the predictor and the criterion (Baron and Kenny, 1986). As a further test of mediation, MacKinnon et al.'s (2002) $z^{\prime}$ test was used to examine the significance of the indirect relationship between the independent variable and the dependent variable via the hypothesized mediator.

\section{Models for the Prediction of PTSD symptoms (IES-R) Direct association model}

We first confirmed the existence of a significant direct relation between groups and PTSD symptoms. We defined the latent PTSD construct (factor) using participants' intrusion, avoidance, and hyperarousal scores as its indicators. This model fit the observed data well $\left(\chi^{2}[2]=2.081, p=0.35, \chi^{2} / d f=1.04, \mathrm{NNFI}=1.0, \mathrm{CFI}=1.00\right.$, RMSEA $=0.01$ [confidence interval (CI), 0.000 to 0.08 ]). As predicted, attorneys were significantly associated with high levels of
PTSD symptoms $(\beta=0.26, t=4.833, p<0.0001)$. This model significantly explained $7 \%$ of the variance in PTSD symptoms.

\section{Mediational association model}

We tested whether work-related exposure (the mediators) significantly reduced (accounted for) the direct relation between groups and PTSD symptoms (the outcome). To do this, we specified a model in which groups had a direct path to PTSD symptoms, as well as an indirect path through work-related exposure variables (controlling for the shared variance among mediators). The mediational model fit the observed data well $\left(\chi^{2}[6]=6.346, p=0.386, \chi^{2} / d f=1.06, \mathrm{NNFI}=1.0\right.$, $\mathrm{CFI}=1.0, \mathrm{RMSEA}=0.01$ [CI, 0.000 to 0.07$]$ ). As noted earlier, the direct path from groups to PTSD symptoms was significant. However, this path became significantly weaker $(\beta=0.09, t=1.46$, not significant $[\mathrm{ns}])$ when hours at work $\left(z^{\prime}=3.06, p<0.01\right)$ and exposure to trauma-exposed clients $\left(z^{\prime}=3.003, p<0.01\right)$ were included in the model. As shown in Figure 1, attorneys were significantly associated with higher hours at work $(\beta=0.50 ; t=10.71, p<0.0001)$, which, in turn, was associated with PTSD symptoms $(\beta=0.20 ; t=3.18, p<$ $0.001)$; moreover, attorneys were significantly associated with higher exposure to trauma-exposed clients $(\beta=0.39 ; t=7.76, p<0.0001)$, which, in turn, was associated with PTSD symptoms $(\beta=0.19 ; t=3.23$, $p<0.001)$. Therefore, the work-related exposure variables mediated (albeit not exclusively) the attorneys' vulnerability to PTSD symptoms. This model significantly explained $14 \%$ of the variance in PTSD symptoms. Therefore, when work-related exposure (the mediators) was included in the model, it added a significant $7 \%$ to the explained variance in PTSD symptoms.

\section{Models for the Prediction of Functional Impairment Levels (SDS)}

\section{Direct association model}

We first confirmed the existence of a significant direct relation between groups and functional impairment. We defined the latent SDS construct (factor) using the participants' SDS scales scores as its 
TABLE 2. Means, SDs, and Prevalence of Cutoff Scores for Outcome Variables

\begin{tabular}{|c|c|c|c|c|c|c|}
\hline & \multicolumn{2}{|c|}{$\begin{array}{c}\text { Attorney } \\
(N=238 ; 69 \%)\end{array}$} & \multicolumn{2}{|c|}{$\begin{array}{c}\text { Administrative Support } \\
\text { Staff }(N=109 ; 31 \%)\end{array}$} & \multirow[b]{2}{*}{$t(d f=343)$} & \multirow[b]{2}{*}{ Effect Size $(d)$} \\
\hline & Mean & SD & Mean & SD & & \\
\hline IES-R intrusion & 0.73 & 0.58 & 0.46 & 0.34 & $4.52 * *$ & 0.52 \\
\hline IES-R avoidance & 0.65 & 0.65 & 0.33 & 0.49 & $4.42 * *$ & 0.51 \\
\hline IES-R hyperarousal & 0.55 & 0.65 & 0.25 & 0.44 & $4.31 * *$ & 0.50 \\
\hline CES-D & 14.08 & 10.27 & 8.91 & 7.68 & $4.66 * *$ & 0.54 \\
\hline$<16$ & \multicolumn{2}{|c|}{144} & \multicolumn{2}{|c|}{88} & \multicolumn{2}{|c|}{$\chi^{2}=13.11^{* *}$} \\
\hline$>16$ & \multicolumn{2}{|c|}{$94(39.5 \%)$} & \multicolumn{2}{|c|}{$21(19.3 \%)$} & & \\
\hline SDS & 9.80 & 6.77 & 3.61 & 4.57 & $8.58 * *$ & 0.99 \\
\hline$<5$ & \multicolumn{2}{|c|}{60} & \multicolumn{2}{|c|}{79} & \multicolumn{2}{|c|}{$\chi^{2}=66.30^{* *}$} \\
\hline ProQOL5 ${ }^{\mathrm{a}}$-BO & 27.36 & 6.09 & 21.57 & 5.36 & $8.47 * *$ & 0.98 \\
\hline$<56$ & \multicolumn{2}{|c|}{149} & \multicolumn{2}{|c|}{100} & \multirow{2}{*}{\multicolumn{2}{|c|}{$\chi^{2}=34.99 * *$}} \\
\hline$>56$ & \multicolumn{2}{|c|}{$89(37.4 \%)$} & \multicolumn{2}{|c|}{$9(8.3 \%)$} & & \\
\hline ProQOL5 ${ }^{\mathrm{a}}$-STS & 21.20 & 5.91 & 16.82 & 4.80 & $6.73 * *$ & 0.78 \\
\hline$<56$ & \multicolumn{2}{|c|}{157} & \multicolumn{2}{|c|}{98} & \multicolumn{2}{|c|}{$\chi^{2}=21.30^{* *}$} \\
\hline$>56$ & \multicolumn{2}{|c|}{$81(34 \%)$} & & & & \\
\hline $\begin{array}{l}{ }^{\text {a }} \text { At the } 75 \text { th percentile. } \\
{ }^{*} p<0.05 \text { (two-tailed) } \\
{ }^{* *} p<0.001 \text { (two-tailed } \\
\text { PTSD indicates posttrau } \\
\text { ProQOL5, Professional Que }\end{array}$ & $\begin{array}{l}\text { rder; I } \\
\text { e vers }\end{array}$ & Events & $\begin{array}{l}\text { CES-D, } \\
\text { Burno }\end{array}$ & $\begin{array}{l}\text { emiolo } \\
\text { dary } \mathrm{Tr}\end{array}$ & $\begin{array}{l}\text { epression Scal } \\
\text { ns, not signif }\end{array}$ & an Disability Scale; \\
\hline
\end{tabular}

indicators. This model fit the observed data well $\left(\chi^{2}[2]=0.70, p=\right.$ $0.71, \chi^{2} / d f=0.35, \mathrm{NNFI}=1.0, \mathrm{CFI}=1.00, \mathrm{RMSEA}=0.000[\mathrm{CI}$, 0.000 to 0.07$])$. As predicted, attorneys were significantly associated with high levels of functional impairment symptoms $(\beta=0.44, t=$ $8.370, p<0.0001)$. This model significantly explained $20 \%$ of the variance in SDS.

TABLE 3. Correlations Between Predictors and Outcome Variables

\begin{tabular}{|c|c|c|c|c|c|c|c|c|}
\hline & \multicolumn{3}{|c|}{ PTSD (IES-R) } & \multicolumn{3}{|c|}{ ProQOL5 } & \multirow[b]{2}{*}{ CES-D } & \multirow[b]{2}{*}{ SDS } \\
\hline & Intrusion & Avoidance & Hyper-Arousal & CS & BO & STS & & \\
\hline Group $^{\mathrm{a}}$ & $0.24 *$ & $0.24 *$ & $0.23 *$ & -0.12 & $0.42 *$ & $0.34 *$ & $0.24 *$ & $0.42 *$ \\
\hline Age & 0.01 & -0.06 & -0.05 & 0.07 & -0.03 & -0.05 & -0.09 & -0.07 \\
\hline Years on the job & 0.10 & 0.04 & 0.05 & 0.00 & 0.09 & 0.09 & 0.03 & 0.08 \\
\hline Average number of hours working & $0.29 *$ & $0.26^{*}$ & $0.25^{*}$ & -0.05 & $0.38 *$ & $0.37 *$ & $0.26^{*}$ & $0.40^{*}$ \\
\hline Childhood not physical and sexual abuse & -0.01 & -0.01 & 0.06 & -0.03 & 0.08 & 0.07 & 0.05 & 0.04 \\
\hline Adulthood physical and sexual abuse & 0.02 & -0.02 & 0.04 & -0.03 & 0.05 & 0.05 & 0.03 & -0.00 \\
\hline Adulthood not physical and sexual abuse & -0.00 & -0.04 & 0.02 & -0.02 & 0.04 & 0.02 & 0.01 & -0.02 \\
\hline Work-related exposure & $0.24 *$ & $0.28 *$ & $0.27 *$ & -0.17 & $0.38 *$ & $0.31 *$ & $0.30 *$ & $0.37 *$ \\
\hline
\end{tabular}

To ensure that the overall chance of a type I error remained less than 0.05 ; we applied a full Bonferroni correction

${ }^{a}$ Group is a binary-coded variable ( 0 , administrative support staff; 1 , attorney).

${ }^{\mathrm{b}} \mathrm{Sex}$ is a binary-coded variable ( 0 , women; 1 , men).

$* p<0.001$ (two-tailed).

PTSD indicates posttraumatic stress disorder; IES-R, Impact of Events Scale-Revised; CES-D, Center for Epidemiological Studies Depression Scale; SDS, Sheehan Disability Scale; ProQOL5, Professional Quality of Life Scale version 5; CS, Compassion Satisfaction; BO, Burnout; STS, Secondary Traumatic Stress. 


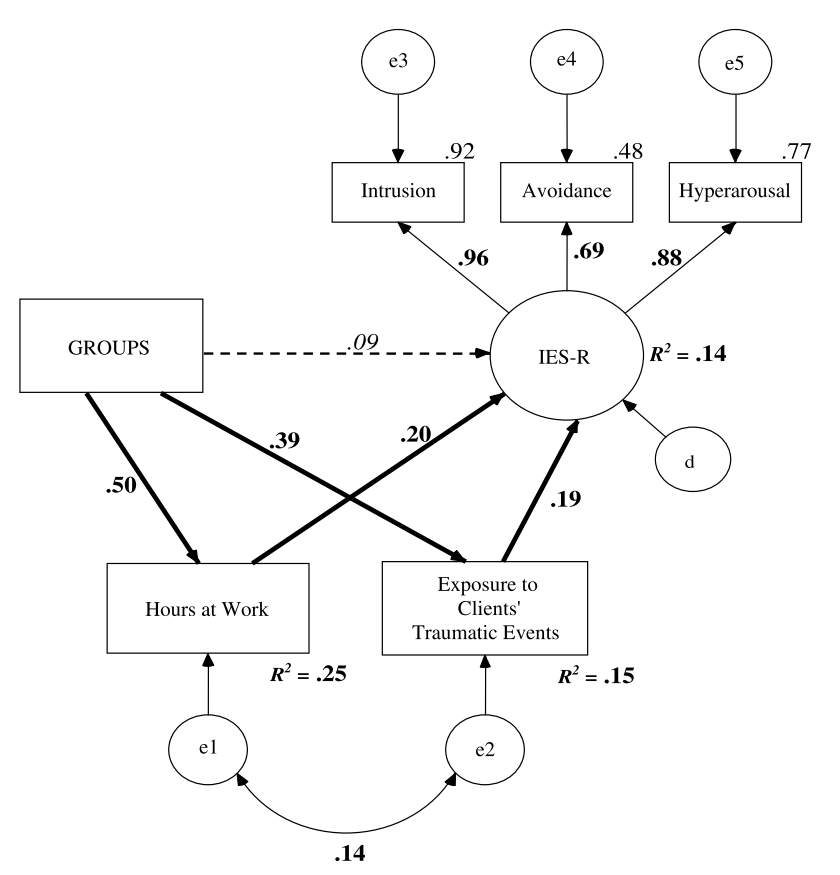

FIGURE 1. Mediational model for PTSD symptom levels (IES-R). Rectangles indicate measured variables and large circles represent latent constructs. Small circles reflect residuals (e) or disturbances (d); bold numbers above or near endogenous variables represent the amount of variance explained $\left(R^{2}\right)$. Unidirectional arrows depict hypothesized directional or "causal" links. Standardized maximum likelihood parameters are used. Bold estimates are statistically significant. GROUPS is a binary-coded variable $(0$, administrative support staff; 1, attorney). IES-R indicates Impact of Events Scale-Revised.

\section{Mediational association model}

We tested whether work-related exposure (the mediators) significantly reduced (accounted for) the direct relation between groups and functional impairment symptoms (the outcome). To do this, we specified a model in which groups had a direct path to SDS symptoms, as well as an indirect path through work-related exposure variables (controlling for the shared variance among mediators). The mediational model fit the observed data well $\left(\chi^{2}[6]=6.103, p=\right.$ $0.412, \chi^{2} / d f=1.02, \mathrm{NNFI}=1.0, \mathrm{CFI}=1.0, \mathrm{RMSEA}=0.007[\mathrm{CI}$, 0.000 to 0.07$]$ ). As noted earlier, the direct path from groups to SDS symptoms was significant. However, this path became significantly weaker $(\beta=0.25, t=4.24, p<0.0001)$ when hours at work $\left(z^{\prime}=\right.$ $3.83, p<0.001)$ and exposure to clients' traumatic events $\left(z^{\prime}=3.60\right.$, $p<0.001)$ were included in the model. As shown in Figure 2, attorneys were significantly associated with higher hours at work $(\beta=0.50 ; t=10.69, p<0.0001)$, which, in turn, was associated with SDS symptoms $(\beta=0.21 ; t=4.09, p<0.0001)$; moreover, attorneys were significantly associated with higher exposure to trauma-exposed clients $(\beta=0.39 ; t=7.78, p<0.0001)$, which, in turn, was associated with SDS symptoms $(\beta=0.19 ; t=4.03, p<0.0001)$. Therefore, workrelated exposure variables mediated (albeit not exclusively) the attorneys' vulnerability to functional impairment symptoms. This model significantly explained $29 \%$ of the variance in SDS. Therefore, when work-related exposure (the mediators) was included in the model, it added a significant $9 \%$ to the explained variance in SDS.

\section{Models for the Prediction of Levels of STS and BO (ProQOL5)}

\section{Direct association model}

We first confirmed the existence of a significant direct relation between groups and ProQOL5 STS and BO. We defined the latent ProQOL5 construct (factor) using participants' STS and BO scales scores as its indicators. This model has zero degrees of freedom; thus, fit indices could not be estimated. As predicted, attorneys were significantly associated with high levels of STS and BO symptoms $(\beta=$ $0.45, t=6.74, p<0.0001)$. This model significantly explained $20 \%$ of the variance in ProQOL5 STS and BO.

\section{Mediational association model}

We tested whether work-related exposure (the mediators) significantly reduced (accounted for) the direct relation between groups and STS and BO symptoms (the outcome). To do this, we specified a model in which groups had a direct path to ProQOL5 symptoms, as well as an indirect path through work-related exposure variables (controlling for the shared variance among mediators). The mediational model fit the observed data well $\left(\chi^{2}[2]=2.939, p=0.23, \chi^{2} / d f=1.47\right.$, $\mathrm{NNFI}=1.0, \mathrm{CFI}=1.0, \mathrm{RMSEA}=0.004$ [CI, 0.000 to 0.08$]$ ). As noted earlier, the direct path from groups to ProQOL5 symptoms was significant. However, this path became significantly weaker $(\beta=0.24$, $t=3.866, p<0.0001)$ when hours at work $\left(z^{\prime}=3.60, p<0.001\right)$ and

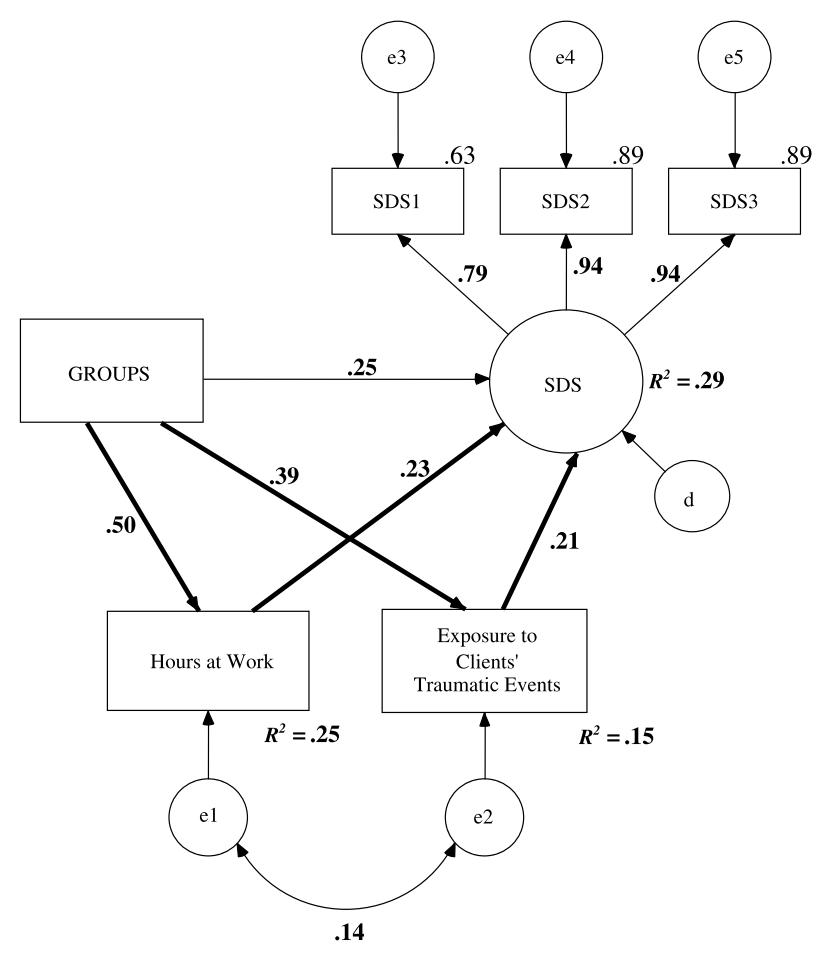

FIGURE 2. Mediational model for functional impairment levels (SDS). Rectangles indicate measured variables and large circles represent latent constructs. Small circles reflect residuals (e) or disturbances (d); bold numbers above or near endogenous variables represent the amount of variance explained $\left(R^{2}\right)$. Unidirectional arrows depict hypothesized directional or "causal" links. Standardized maximum likelihood parameters are used. Bold estimates are statistically significant. GROUPS is a binary-coded variable (0, administrative support staff; 1, attorney). SDS indicates Sheehan Disability Scale. 


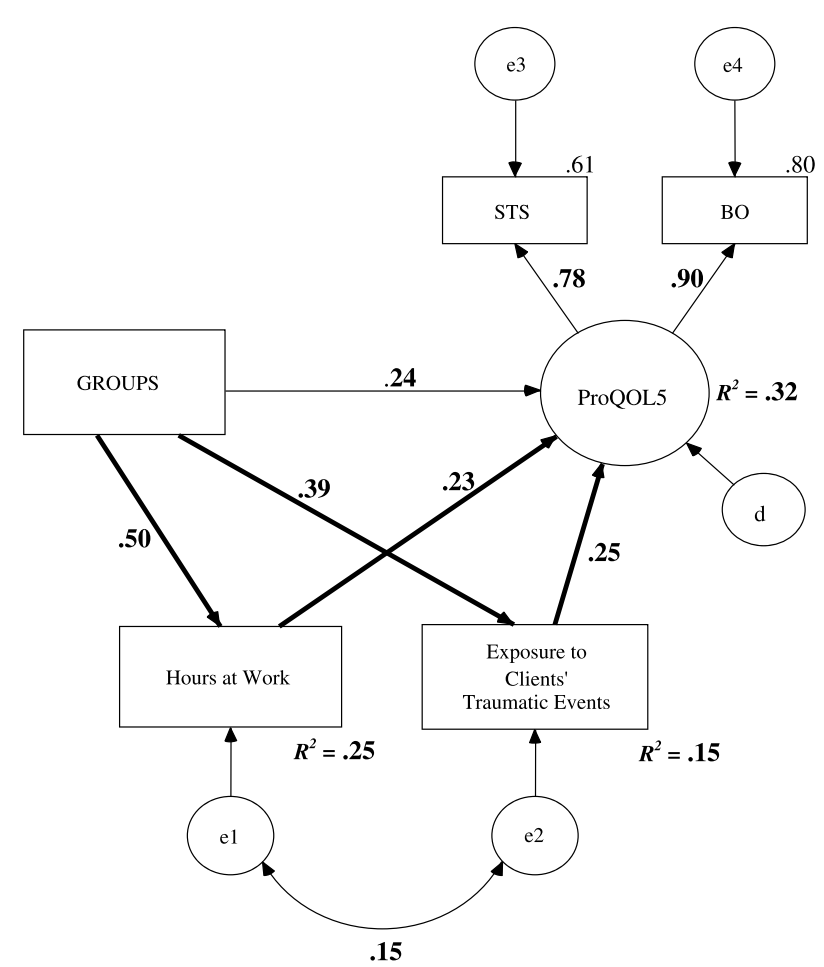

FIGURE 3. Mediational model for secondary traumatic stress and burnout levels (ProQOL5). Rectangles indicate measured variables and large circles represent latent constructs. Small circles reflect residuals (e) or disturbances (d); bold numbers above or near endogenous variables represent the amount of variance explained $\left(R^{2}\right)$. Unidirectional arrows depict hypothesized directional or "causal" links. Standardized maximum likelihood parameters are used. Bold estimates are statistically significant. GROUPS is a binary-coded variable (0, administrative support staff; 1 , attorney). ProQOL5 indicates Professional Quality of Life Scale version 5.

exposure to trauma-exposed clients $\left(z^{\prime}=3.85, p<0.001\right)$ were included in the model. As shown in Figure 3, attorneys were significantly associated with higher hours at work $(\beta=0.50 ; t=10.70$, $p<0.0001)$, which, in turn, was associated with ProQOL5 symptoms $(\beta=0.23 ; t=3.81, p<0.0001)$; moreover, attorneys were significantly associated with higher exposure to trauma-exposed clients $(\beta=0.39 ; t=7.80, p<0.0001)$, which, in turn, was associated with ProQOL5 symptoms $(\beta=0.25 ; t=4.38, p<0.0001)$. Therefore, workrelated exposure variables mediated (albeit not exclusively) the attorneys' vulnerability to STS and BO symptoms. This model significantly explained $32 \%$ of the variance in ProQOL5 STS and BO. Therefore, when work-related exposure (the mediators) was included in the model, it added a significant $12 \%$ to the explained variance in ProQOL5 STS and $\mathrm{BO}$.

\section{Models for the Prediction of Depressive Symptoms (CES-D)}

\section{Direct association model}

We first confirmed the existence of a significant direct relation between groups and depressive symptoms. We defined the observed variable CES-D scores. This model has zero degrees of freedom; thus, fit indices could not be estimated. As predicted, attorneys were significantly associated with high levels of depressive symptoms $(\beta=0.24$, $t=4.67, p<0.0001)$. This model significantly explained $6 \%$ of the variance in CES-D symptoms.

\section{Mediational association model}

We tested whether work-related exposure (the mediators) significantly reduced (accounted for) the direct relation between groups and depressive symptoms (the outcome). To do this, we specified a model in which groups had a direct path to CES-D symptoms, as well as an indirect path through work-related exposure variables (controlling for the shared variance among mediators). This model (Fig. 4) has zero degrees of freedom; thus, fit indices could not be estimated. As noted earlier, the direct path from groups to CES-D symptoms was significant. However, this path became significantly weaker $(\beta=0.08$, $t=1.39$, ns $)$ when hours at work $\left(z^{\prime}=2.45, p<0.05\right)$ and exposure to trauma-exposed clients $\left(z^{\prime}=3.20, p<0.01\right)$ were included in the model. As shown in Figure 4, attorneys' were significantly associated with higher hours at work $(\beta=0.50 ; t=10.72, p<0.0001)$, which, in turn, was associated with CES-D symptoms $(\beta=0.15 ; t=2.51, p<$ $0.05)$; moreover, attorneys were significantly associated with higher exposure to trauma-exposed clients $(\beta=0.39 ; t=7.76, p<0.0001)$, which, in turn, was associated with CES-D symptoms $(\beta=0.22$; $t=3.90, p<0.0001)$. Therefore, work-related exposure variables mediated (albeit not exclusively) the attorneys' vulnerability to depressive symptoms. This model significantly explained $12 \%$ of the variance in CES-D symptoms. Therefore, when work-related exposure

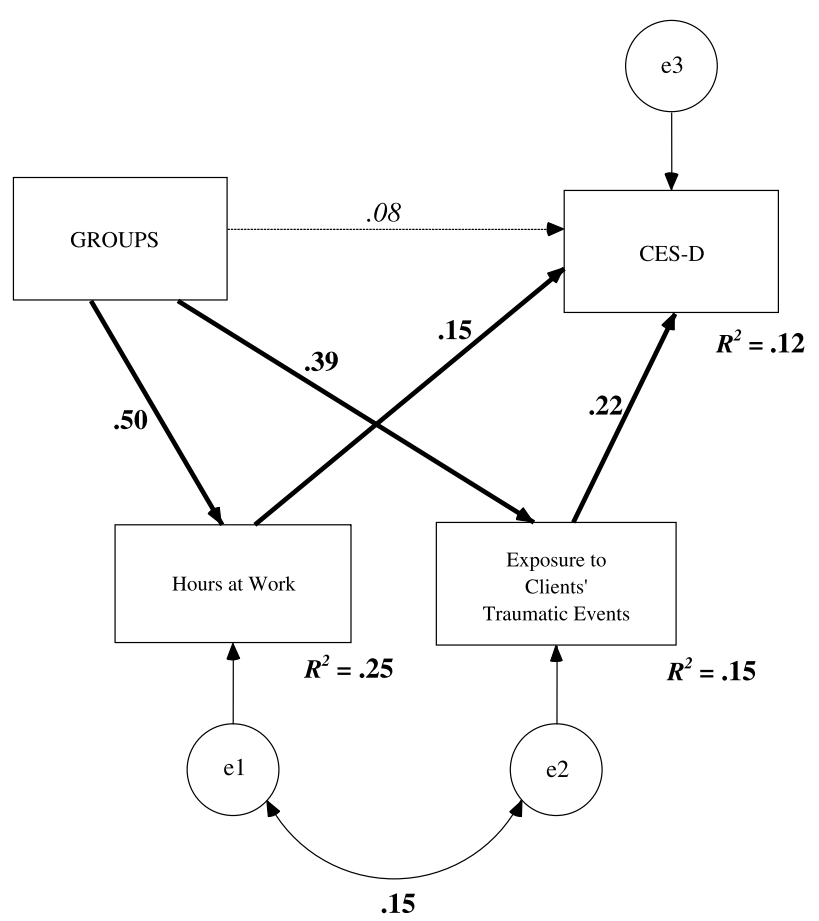

FIGURE 4. Mediational Model for Depressive Symptoms Levels (CES-D). Rectangles indicate measured variables and large circles represent latent constructs. Small circles reflect residuals (e) or disturbances (d); bold numbers above or near endogenous variables represent the amount of variance explained $\left(R^{2}\right)$. Unidirectional arrows depict hypothesized directional or "causal" links. Standardized maximum likelihood parameters are used. Bold estimates are statistically significant. GROUPS is a binary-coded variable ( 0 , administrative support staff; 1, attorney). CES-D indicates Center for Epidemiological Studies Depression Scale. 
(the mediators) was included in the model, it added a significant $6 \%$ to the explained variance in CES-D symptoms.

\section{DISCUSSION}

To our knowledge, this is the largest study of attorneys' emotional responses to work with clients who have experienced or have been directly involved with trauma. Our data, collected from 238 attorneys and 109 administrative support staff of the Wisconsin State Public Defender Office, indicated a significant level of distress among the attorneys compared with administrative support staff. Measures of PTSD symptoms, depression, functional impairment, BO, and STS were consistently higher among attorneys compared with administrative support staff, which was predicted given the longer work hours and higher level of exposure to clients with a history of trauma among the attorneys. Bivariate analysis demonstrated that these measures of distress were, in fact, significantly correlated with hours worked per week and the number of trauma-exposed clients. Subsequent SEM modeling illustrated that work-related exposure variables (hours at work and number of trauma-exposed clients) were significant, albeit not exclusive, mediators of the differences of group membership on symptoms. Therefore, although both attorneys and administrative support staff were exposed to trauma-exposed clients, the attorneys' longer work hours and greater direct contact with these clients associated with their vulnerability to PTSD symptoms, depression, functional impairment, STS, and BO compared with the administrative support staff's indirect exposure to these trauma-exposed clients.

The findings of this study confirmed the results of earlier small studies (Levin and Greisberg, 2003; Vrlevski and Franklin, 2008) and also demonstrated a significant relationship between work and exposure variables and depression and functional impairment. Specifically, we found significant impairment in the attorney group, with $74.8 \%$ scoring above threshold on the SDS, 39.5\% demonstrating significant symptoms of depression (compared with the earlier findings of a $20 \%$ rate of depression in attorneys [Benjamin et al., 1990; Eaton et al., 1990]), more than a third scoring above the 75th percentile on STS and $\mathrm{BO}$, and $11 \%$ with clinically significant PTSD symptoms. In a recent review of secondary trauma, Elwood et al. (2011) pointed out that the secondary trauma literature has largely failed to characterize impairment in professionals experiencing secondary trauma. It appears that at least for attorneys working in the public defender setting, PTSD, secondary trauma, and $\mathrm{BO}$ symptoms are accompanied by significant impairment and rates of depression (Kessler et al., 1994) and PTSD (Kessler et al., 1995) greater than those reported in community samples. In addition, the attorneys reported less compassion satisfaction on the ProQOL5 compared with administrative support staff, and only a minority in both groups reported high levels of satisfaction with their work. Linley and Joseph (2007), also using the ProQOL, found the therapeutic bond was the best predictor of compassion satisfaction in a sample of therapists. This suggests a need to better characterize the relationship between public defenders and their clients and its impact on work satisfaction, particularly given Lynch's (1997) finding that public defenders felt stressed by encountering angry clients and families.

Our SEM analysis raises a question concerning the relative contribution of general workload as measured in hours per week compared with that of exposure to traumatized clients, given that each made nearly equal contributions to the outcome measures. Although Figley (1995) proposed that secondary trauma is "the stress resulting from helping or wanting to help a traumatized or suffering person" (p. 7), Regehr et al. (2004) found that work load stressors such as documentation and lack of resources, as well as public scrutiny and organizational issues, played a stronger role in mediating STS and depression compared with client exposure. The stress of the work setting itself, particularly a public legal setting where attorneys have high caseloads, are often not valued by clients, the justice system, or society and generally lack sufficient resources appears to make at least an equal contribution to overall distress (see also Lynch, 1997). Future studies are needed to better characterize the relationships between these stressors and attorneys' symptoms and functioning.

In contrast with the previous study by Vrlevski and Franklin (2008), no relationships were found between personal trauma and distress variables. Given that the literature for mental health providers is inconsistent (Brady et al., 1999 versus Boscarino et al., 2004), our finding is expectable. The disparate findings across studies may be related to the challenges of accurately measuring past trauma, that is, the subjects' hesitancy to record this information and their widely varying interpretations of this type of question. The two other findings were the lack of impact of sex or years on the job. Because previous literature studying therapists has found female sex predictive of STS (Kassam-Adams, 1999) our finding raises questions about differences between attorneys and their administrative support staff and mental health professionals. Regarding years on the job, available results are contradictory, at times indicating greater risk of symptoms of STS and $\mathrm{BO}$ with increasing years on the job (e.g., Jaffe et al., 2003) versus a protective effect of greater experience (Maslach et al., 2001; Pearlman and Mac Ian, 1995), suggesting that this variable is multidimensional and that its effects vary in different settings.

What emerges is that similar to mental health professionals, attorneys working as public defenders with clients who have experienced or have been directly involved in trauma are at high risk of developing clinically significant symptoms of secondary trauma and $\mathrm{BO}$ as well as depression and functional impairment. Our study adds a potential mechanism by which this high vulnerability is a result of the intensity of their exposure and the length of work hours. These findings point to the need to support attorneys in identifying the development of these symptoms and to implement interventions to reduce them. The current trend is to encourage professionals with STS and BO to seek peer and supervisory support, increase leisure and physical activity, seek counseling and psychiatric treatment as needed, and develop a variety of resiliency skills (e.g., Gentry et al., 2002). However, Bober and Regher (2006) found that these individual approaches did not reduce traumatic stress scores. Instead, they recommended institutional interventions. Our findings reinforce this more nuanced picture and suggest that emphasis must be placed on reducing long work hours as well as on the extent of client exposure such as the rotation of attorneys between different types of services. Given that public defender services are underfunded and overloaded, these types of institutional changes remain a significant challenge.

There are several limitations to this study. Our study's crosssectional nature limits any assignment of causality; our model cannot provide a definitive answer to the question of the direction of the observed effects. One might argue that mediation variables may have been affected by the outcome variables, that is, attorneys with more symptoms and impairment may have worked longer hours because of low efficiency or may have been attracted to work with clients who had experienced trauma. Second, the administrative support staff may not have represented the best comparison group. Although this group did provide a good comparator because of differences in work and exposure variables, another group of attorneys working with clients with no trauma exposure (e.g., corporate attorneys) may have been a better comparison, particularly given that attorneys and support staff differ in education and responsibilities. The administrative support staff group also had significantly fewer men than the attorney group, although the absence of a relationship between sex and outcomes suggests that this difference did not affect the study's findings.

Despite these limitations, our naturalistic study investigated a unique phenomenon that may well have significant ecological validity. To the best of our knowledge, the present study represents the first attempt to apply SEM analysis to the association between indicators 
of STS symptoms and to examine the mediating role of work-related exposure in attorneys and administrative support staff. Our findings highlight the importance of theoretical models that include job-related description (direct versus indirect exposure to clients' traumatic events) and related job exposure (intensity and amount of exposure) and their role in the development of symptoms and impairment.

\section{CONCLUSIONS}

Attorneys working in the Wisconsin State Public Defender Office demonstrated significantly higher levels of PTSD symptoms, depression, STS, BO, and functional impairment compared with administrative support staff. This difference was mediated by attorneys' longer work hours and greater contact with clients who had experienced trauma. These findings suggest a need to support attorneys and administrative support staff experiencing these symptoms and to address high workloads as well as the intensity of contact with traumaexposed clients.

\section{ACKNOWLEDGMENTS}

The authors thank Beth Stamm, PhD, for her input on the use and scoring of the ProQOL5 as well as the overall design and Jeff Apotheker, PhD, for his critique of the original design and support of the submission to the research committee. They also thank all of the participants in this study. Finally, they thank the reviewers for their constructive suggestions and comments on an earlier draft of this paper.

\section{DISCLOSURE}

This study was supported by the State Bar of Wisconsin and the Wisconsin State Public Defender Office.

The authors have nothing to disclose.

\section{REFERENCES}

Allegretti J (1993) Shooting elephants, serving clients: An essay on George Orwell and the lawyer-client relationship. Creighton Law Rev. 27:1-24.

American Psychiatric Association (1994) Diagnostic and statistical manual of mental disorders (4th ed). Washington, DC: American Psychiatric Association.

Arbuckle JL (2009) Amos: A structural equation modeling program. Chicago, IL: Small Waters.

Baird S, Jenkins SR (2003) Vicarious traumatization, secondary traumatic stress, and burnout in sexual assault and domestic violence agency staff. Violence Vict. 18:71-86

Baron RM, Kenny DA (1986) The moderator-mediator variable distinction in social psychological research: Conceptual, strategic, and statistical considerations. J Pers Soc Psychol. 51:1173-1182.

Benjamin GA, Darling EJ, Sales B (1990) The prevalence of depression, alcohol abuse, and cocaine abuse among United States lawyers. Int J Law Psychiatry. 13:233-246.

Bentler PM, Bonnet DC (1980) Significance tests and goodness of fit in the analysis of covariance structures. Psychol Bull. 88:588-606.

Bober T, Regher C (2006) Strategies for reducing secondary or vicarious trauma: Do they work? Brief Treat Crisis Interv. 6:1-9.

Boscarino JA, Figley CR, Adams RE (2004) Compassion fatigue following the September 11 terrorist attacks: A study of secondary trauma among New York City social workers. Int J Emerg Ment Health. 6:57-66.

Brady JL, Guy JD, Poelstra PL, Brokaw BF (1999) Vicarious traumatization, spirituality, and the treatment of sexual abuse survivors: a national survey of women therapists. Prof Psychol Res Pract. 30:586-393.

Bride BE, Jones JL, Macmaster SA (2007) Correlates of secondary traumatic stress in child protective services workers. J Evid-Based Soc Work. 4:69-80.

Creamer M, Bell R, Failla S (2003) Psychometric properties of the impact of event scale-revised. Behav Res Ther. 41:1489-1496.
Creamer T, Liddle B (2005) Secondary traumatic stress among disaster mental health workers responding to the September 11 attacks. J Trauma Stress. 18:89-96.

Devilly GJ, Wright R, Varker T (2009) Vicarious trauma, secondary traumatic stress or simply burnout? Effect of trauma therapy on mental health professionals. Aust N Z J Psychiatry. 43:373-385.

Eaton WW, Anthony JC, Mandel W, Garrison R (1990) Occupations and the prevalence of major depressive disorder. J Occup Med. 32:1079-1087.

Eaton WW, Smith C, Ybarra M, Muntaner C, Tien A (2004) Center for Epidemiologic Studies Depression Scale: Review and revision (CESD and CESD-R). In Maruish ME (Ed), The use of psychological testing for treatment planning and outcomes assessment: Vol. 3: Instruments for adults (pp 363-377). Princeton, NJ: Lawrence Erlbaum Associates.

Elwood LS, Mott J, Lohr JM, Galovski TE (2011) Secondary trauma symptoms in clinicians: A critical review of the construct, specificity, and implications for trauma-focused treatment. Clin Psychol Rev. 31:25-36.

Erikson CB, Kemp HV, Gorsuch R, Hoke S, Foy DW (2001) Trauma exposure and PTSD symptoms in international relief and development personnel. $J$ Trauma Stress. 14:205-212.

Farber BA, Heifetz L (1982) The process and dimensions of burnout in psychotherapists. Prof Psychol. 13:293-301.

Figley CR (1995) Compassion fatigue as secondary traumatic stress disorder: an overview. In Figley CR (Ed), Compassion fatigue: Coping with secondary traumatic stress disorder in those who treat the traumatized (pp 1-20). Levittown, PA: Brunner/Mazel.

Frazier PA, Tix AP, Barron KE (2004) Testing moderator and mediator effects in counseling psychology research. J Couns Psychol. 51:115-134.

Gentry EJ, Baranowsky AB, Dunning K (2002) The accelerated recovery program (ARP) for compassion fatigue. In Figley CR (Ed), Treating compassion fatigue (pp 123-138). New York: Brunner-Routledge.

Gomme IM, Hall MP (1995) Prosecutors at work: role overload and strain. J Crim Justice. 15:191-200.

Hoyle RH, Smith GT (1994) Formulating clinical research hypotheses as structural equation models: A conceptual overview. J Consult Clin Psychol. 62:429-440.

Hu LT, Bentler PM (1999) Cutoff criteria for fit indexes in covariance structure analysis: Conventional criteria versus new alternatives. Struct Equ Modeling. 6:1-55.

Jaffe PG, Crooks CV, Dunford-Jackson BL, Town M (2003) Vicarious trauma in judges: The personal challenge of dispensing justice. Juv Fam Court J. 54:1-9.

Jenkins SH, Baird S (2002) Secondary traumatic stress and vicarious trauma: A validation study. J Trauma Stress. 15:423-432.

Jöreskog KG, Sörbom D (1993) LISREL 8: Structural equation modeling with the SIMPLIS command language. Chicago: Scientific Software International.

Kassam-Adams N (1999) The risks of treating sexual trauma: Stress and secondary trauma in psychotherapists. In Stamm BH (Ed), Secondary traumatic stress (pp 37-48). Lutherville, ME: Sidran Press.

Kelloway E K (1998) Using lisrel for structural equation modeling: A researcher's guide. Newbury Park, CA: Sage.

Kenny DA, Kashy DA, Bolger N (1998) Data analysis in social psychology. In Gilbert D, Fiske S, Lindzey G (Eds), The handbook of social psychology (4th ed, pp 233-265). New York: McGraw-Hill.

Kenny DA, McCoach DB (2003) Effect of the number of variables on measures of fit in structural equation modeling. Struct Equ Modeling. 10:333-351.

Kessler RC, McGonagle KA, Zhao S, Nelson CB, Hughes M, Eshleman S, Wittchen H, Kendler KS (1994) Lifetime prevalence and 12-month prevalence of DSM-III-R psychiatric disorders in the United States: Results from the national comorbidity survey. Arch Gen Psychiatry. 51:8-19.

Kessler RC, Sonnega A, Bromet E, Hughes M, Nelson CB (1995) Posttraumatic stress disorder in the national comorbidity survey. Arch Gen Psychiatry. 52:1048-1060.

Landry SH, Smith KE, Swank PR, Miller-Loncar CL (2000) Early maternal and child influences on children's later independent cognitive and social functioning. Child Dev. 71:358-375.

Levin AP, Greisberg S (2003) Vicarious trauma in attorneys. Pace Law Rev. 2:245-257.

Linley PA, Joseph S (2007) Therapy work and the therapist's positive and negative well-being. J Soc Clin Psychol. 26:385-403.

Ljubotina D, Muslic L (2003) Convergent validity of four instruments for measuring posttraumatic stress disorder. Rev Psychol. 10:11-21.

Lynch DR (1997) The nature of occupational stress among public defenders. Justice Syst J. 19:17-35. 
MacKinnon DP, Lockwood CM, Hoffman J M, West SG, Sheets V (2002) A comparison of methods to test mediation and other intervening variable effects. Psychol Methods. 7:83-104.

Maslach C, Schaufeli WB, Leiter MP (2001) Job burnout. Annu Rev Psychol. 52:397-422.

McCann IL, Pearlman LA (1990) Vicarious traumatization: A framework for understanding the psychological effects of working with victims. J Trauma Stress. 3:131-149.

Meier JS (1993) Notes from the underground: Integrating psychological and legal perspectives on domestic violence in theory and practice. Hofstra Law Rev. 21:1295-1366.

Ortlepp K, Friedman M (2002) Prevalence and correlates of secondary traumatic stress in workplace lay trauma counselors. J Trauma Stress. 15:213-222.

Pearlman LA, Mac Ian P S (1995) Vicarious traumatization: An empirical study of the effects of trauma work on trauma therapists. Prof Psychol Res Pract. 26:558-565.

Piwowarcyzy L, Ignatius S, Crosby S, Grodin M, Heeren T, Sharma A (2009) Secondary trauma in asylum lawyers. Bender's Immigr Bull. 14:263-269.

Radloff LS (1977) The CES-D scale: A self-report depression scale for research in the general population. Appl Psychol Meas. 1:385-401.
Regehr C, Hemsworth D, Leslie B, Howe P, Chau S (2004) Predictors of posttraumatic distress in child welfare workers: A linear structural equation model. Child Youth Serv Rev. 26:331-346.

Schnaube LJ, Frazier PA (1995) Vicarious trauma: the effects of female counselors of working with sexual violence survivors. Psychol Women Q. 19:49-64.

Sheehan DV, Harnett-Sheehan K, Raj BA (1996) The measurement of psychopharmacology. Int Clin Psychopharm. 11:89-95.

Silver MA (1999) Love, hate, and other emotional interference in the lawyer/client relationship. Clin Law Rev. 6:259-313.

Stamm BH (2010) The ProQOL 5 (Professional Quality of Life Scale: Compassion Satisfaction and Compassion Fatigue, version 5). Pocatello, ID: ProQOL.org. Available at: http://www.proqol.org/. Accessed on June 26, 2011.

Vrlevski LP, Franklin J (2008) Vicarious trauma: The impact on solicitors of exposure to traumatic material. Traumatology. 14:106-118.

Weiss D, Marmar C (1997) The Impact of Event Scale-Revised. In Wilson J, Keane T (Eds), Assessing psychological trauma and PTSD (pp 399-411). New York: Guilford. 